\title{
Paramountcy of platelet parameters in thrombocytopenia- Our hospital experience
}

\author{
K. Geetha Mala ${ }^{1, *}$, Bhumika J Bhandari², Shreekant K Kittur ${ }^{3}$ \\ ${ }^{\mathbf{1}}$ Assistant Professor, ${ }^{2}$ Post Graduate, ${ }^{3}$ Professor and Head, Dept. of Pathology, Belagavi Institute of Medical Sciences, Belgaum, \\ Karnataka, India
}

*Corresponding Author: K. Geetha Mala

Email: drgeethamala@gmail.com

Received: $20^{\text {th }}$ March, 2018

Accepted: $18^{\text {th }}$ June, 2018

\begin{abstract}
Introduction: Thrombocytopenia defined as platelet count below 1,50,000/ul. This fall in platelet count may be due to decreased production, increased destruction and pooling of platelets. The platelet parameters include platelet count, mean platelet volume (MPV), platelet distribution width (PDW) obtained by automated cell counters. These help in knowing the pathomechanism of myriad cases of TCPs. Hence the present study was undertaken to know the variations and correlations of platelet parameters in various causes of TCPs.

Materials and Methods: 700 blood samples of patients with platelet count $<1,50,000 / \mathrm{ul}$ and 600 control group samples with normal platelet count $>1,50,000 / \mathrm{ul}$ were studied. Hematological analysis was done by Sysmex KX-21. Platelet parameters of all the cases and control group were noted. The cases were grouped into various categories of A, B or C depending on mechanism of decrease in platelets. Data was analyzed and tested for statistical significance using one-way ANOVA and post hoc testing using Tukey's test.

Results: Majority of the cases in the present study were in group A (75.3\%), followed by group B (23.9\%) and group C (0.6\%). A higher value of MPV $(10.15 \pm 1.30 \mathrm{fl})$ and PDW $(14.44 \pm 2.35 \%)$ was found in group A compared to other categories. Significant results of MPV and PDW values were seen in group A and group B category.

Conclusion: Platelet parameters like MPV and PDW obtained by automated cell counters together with platelet counts help us to know the pathomechanism of various causes of TCPs which inturn provides pivotal information for better management.
\end{abstract}

Keywords: Thrombocytopenia, Platelet count, Mean platelet count, Platelet distribution width.

\section{Introduction}

Thrombocytopenia is defined as platelet count below 1,50,000/ul. This fall in platelet count may be due to decreased production in bone marrow, increased destruction in blood and pooling of platelets. This adequate knowledge of the cause and clinical course of the pathology is pivotal for the better management of thrombocytopenia (TCP). ${ }^{1-4}$ Over the period of time; bone marrow aspiration study remained the gold standard for knowing the cause for thrombocytopenia. But the procedure is invasive, time consuming and carries risk of bleeding during TCP. ${ }^{1-2}$ Being in the era of technology; automated cell counters can be used widely which provides us the valuable information regarding various blood cell parameters that is red blood cells, white blood cells and platelets. The platelet parameters include platelet count (PC), mean platelet volume (MPV) and platelet distribution width (PDW) which are made on peripheral blood platelets. Combined interpretation of these platelet parameters helps in the diagnosis of myriad causes for TCP. ${ }^{1-7}$ Hence the present study was undertaken know the variations and correlations of platelet count, MPV, PDW in various causes of TCPs.

\section{Materials and Methods}

This is a prospective study carried over a period of six months from March 2016 to august 2016, department of pathology, Belgaum institute of medical sciences, Belagavi. 700 blood samples of patients with platelet count $<1,50,000 / \mathrm{ul}$ and 617 control group samples with normal platelet count $>1,50,000 /$ ul were studied. Blood sample was collected in EDTA vacutainers and analysis was done by sysmex KX-21 automated hematology analyzer within 2-6 hours of collection. Platelet parameters that are platelet count, MPV and PDW of all the cases and control group were noted. Every case of TCP was reassessed by peripheral smear examination. Prior ethical clearance for the study and informed consent from the patients were obtained. The cases that had sufficient clinicohematological work up were included in the study, grouped into various categories $\mathrm{A}, \mathrm{B}$ or $\mathrm{C}$ depending on mechanism of TCP and data was analyzed.

\section{Statistical Analysis}

For this study, demographic data of the population was obtained using frequency based analyses. This helped to gain better understanding regarding the age and sex of the study population as well as the diagnosis within each group. The platelet parameters were calculated for each group and presented along with the mean and standard deviation. Comparison of the platelet parameters between the different groups as well as the control was carried out with the help of standard t-tests. The results were tabulated and analyzed. A more detailed multiple comparisons were carried out using a one-way ANOVA and the post hoc testing was done 
using Tukey's test. This helped to determine whether there was significance between the groups and the exact nature of this significance, with the $\mathrm{p}$ values being examined to confirm if findings were significant. The p- value $<0.05$ was considered significant. All the statistical analyses were carried out using SPSS version 24(IBN, Chicago, USA).

\section{Results}

In the present study out of 700 cases; 617 cases of TCP patients had all the details of clinical impressions, platelet count, MPV and PDW. Cases were grouped according to the most predominant mechanism similar to a study done by Reddy $\mathrm{S}$ et al. ${ }^{8}$ The majority of the patients were males, making up $399(64.7 \%)$ of the population and the remaining $218(35.3 \%)$ were females. Ages of the patients ranged from 1 day (neonatal cases) to 85 years. Most of the individuals were between 21 and 30 years of age $(21 \%)$.

Cases were grouped according to predominant mechanism of thrombocytopenia, Group AAccelerated platelet destruction, Group B- Impaired platelet production and Group C- Abnormal platelet pooling. Majority of the cases in the present study were of group A (75.3\%), followed by group B (23.9\%) and group C $(0.6 \%)$. In group A infections $(60.2 \%)$ were the commonest category. In group B anemias (66.2\%) were the commonest. In group $\mathrm{C}$, all cases were of splenomegaly $(0.6 \%)$. (Table 1 ) Based on this classification, the mean and standard deviation of the platelet parameters in each group was obtained, and is given in Table 2. From this table, it could be seen that that accelerated destruction and abnormal pooling group showed the higher values for all platelet parameters and impaired production group had lowest values.

The platelet parameters of the individually diagnosed cases within each broad group were examined. These results can be seen in Table 3. In group A, lowest PC was seen in burns cases $(33000 \pm 32526.91)$, MPV was highest in ITP cases $(11.55 \pm 0.35 \mathrm{fL})$ and least in liver diseases $(9.9 \pm 0.76$ fL). PDW was highest again in ITP cases $(15.70 \pm 3.25 \%)$ and least in sepsis $(13.04 \pm 2.35 \%)$. In group B, MPV was highest in leukemia cases $(9.60 \pm 0.57 \mathrm{fL})$ and least in anemias $(7.98 \pm 1.43 \mathrm{fL})$. PDW was highest again in leukemia cases $(15.35 \pm 5.16 \%)$ and least in aplastic anemia case $(8.1 \%)$. In group $\mathrm{C}$, there were only the cases of splenomegaly with MPV $10.6 \pm 1.25 \mathrm{fL}$ and PDW $15.25 \pm 1.82 \%$.

The significances of different parameters were compared with control group by using an ANOVA and Tukey's test was used as a post hoc test (Table 4). The tabulation shows that platelet count was significant in all the three groups $\mathrm{A}, \mathrm{B}, \mathrm{C}$ when compared with control group. MPV was found significant in group A and $\mathrm{B}$ with control group; but not significant in group C versus control group. PDW also showed the similar significant results among group A, B with control cases but not in group $\mathrm{C}$.

Table 1: Distribution of cases in various categories

\begin{tabular}{|l|c|c|c|c|}
\hline \multicolumn{1}{|c|}{ Cases } & $\begin{array}{c}\text { Group A } \\
\text { Accelerated destruction }\end{array}$ & $\begin{array}{c}\text { Group B } \\
\text { Impaired production }\end{array}$ & $\begin{array}{c}\text { Group C } \\
\text { Abnormal pooling }\end{array}$ & Total \\
\hline Infections & $280(60.2 \%)$ & - & - & $280(45.3 \%)$ \\
\hline Neonatal & $67(14.4 \%)$ & - & - & $67(10.8 \%)$ \\
\hline Cardiac & $54(11.6 \%)$ & - & - & $54(8.8 \%)$ \\
\hline Pregnancy & $34(7.3 \%)$ & - & - & $34(5.5 \%)$ \\
\hline Renal & $24(5.1 \%)$ & - & - & $24(3.8 \%)$ \\
\hline Liver & $8(1.7 \%)$ & - & - & $8(1.2 \%)$ \\
\hline Sepsis & $8(1.7 \%)$ & - & - & $8(1.2 \%)$ \\
\hline ITP & $2(0.4 \%)$ & - & - & $2(0.3 \%)$ \\
\hline Burns & $2(0.4 \%)$ & - & - & $2(0.3 \%)$ \\
\hline Anemias & - & $98(66.2 \%)$ & - & $98(15.8 \%)$ \\
\hline Leukemia & - & $15(10.1 \%)$ & - & $15(2.4 \%)$ \\
\hline Pancytopenia & - & $28(18.9 \%)$ & - & $28(4.5 \%)$ \\
\hline Postchemotherapy & - & $6(4 \%)$ & - & $6(0.9 \%)$ \\
\hline Aplastic anemia & - & $1(0.6 \%)$ & - & $1(0.1 \%)$ \\
\hline Splenomegaly & - & - & $4(100 \%)$ & $4(0.6 \%)$ \\
\hline Total & $465(75.3 \%)$ & $148(23.9 \%)$ & $4(0.6 \%)$ & $617(100 \%)$ \\
\hline
\end{tabular}

Table 2: Platelet parameters according to each group

\begin{tabular}{|l|c|c|c|c|}
\hline \multicolumn{1}{|c|}{ Group } & Number & PC & MPV (fL) & PDW (\%) \\
\hline Accelerated destruction of platelets & 465 & $90641 \pm 30761.15$ & $10.15 \pm 1.30$ & $14.44 \pm 2.35$ \\
\hline Impaired production & 148 & $83483 \pm 29500.71$ & $8.52 \pm 1.69$ & $12.00 \pm 2.64$ \\
\hline Abnormal pooling & 4 & $110750 \pm 28087.66$ & $10.6 \pm 1.25$ & $15.25 \pm 1.82$ \\
\hline Control & 617 & $259160 \pm 67846.8$ & $10.15 \pm 1.29$ & $13.53 \pm 2.78$ \\
\hline
\end{tabular}


Table 3: Platelet parameters in accelerated destruction of platelets- Group A

\begin{tabular}{|l|c|c|c|c|}
\hline \multicolumn{1}{|c|}{ Group A cases } & Number (\%) & PC & MPV (fL) & PDW (\%) \\
\hline Infections & $280(60.2 \%)$ & $92456 \pm 30153.48$ & $10.26 \pm 1.34$ & $14.73 \pm 2.32$ \\
\hline Neonatal & $67(14.4 \%)$ & $87522 \pm 31246.99$ & $10.09 \pm 1.29$ & $14.08 \pm 2.32$ \\
\hline Cardiac & $54(11.6 \%)$ & $91943 \pm 29172.18$ & $10.16 \pm 1.19$ & $13.90 \pm 2.39$ \\
\hline Pregnancy & $34(7.3 \%)$ & $94303 \pm 26640.53$ & $9.78 \pm 1.57$ & $14.32 \pm 2.52$ \\
\hline Renal & $24(5.1 \%)$ & $106909 \pm 21886.96$ & $10.34 \pm 1.09$ & $13.92 \pm 2.03$ \\
\hline Liver & $8(1.7 \%)$ & $98500 \pm 29990.47$ & $9.9 \pm 0.76$ & $14.68 \pm 2.58$ \\
\hline Sepsis & $8(1.7 \%)$ & $87500 \pm 26592.16$ & $9.11 \pm 0.96$ & $13.04 \pm 2.35$ \\
\hline ITP & $2(0.4 \%)$ & $47500 \pm 45961.94$ & $11.55 \pm 0.35$ & $15.70 \pm 3.25$ \\
\hline Burns & $2(0.4 \%)$ & $33000 \pm 32526.91$ & $10.70 \pm 0.57$ & $14.25 \pm 0.78$ \\
\hline
\end{tabular}

Table 4: Platelet parameters in impaired production of platelets- Group B

\begin{tabular}{|l|c|c|c|c|}
\hline \multicolumn{1}{|c|}{ Group B cases } & Number $(\%)$ & PC & MPV (fL) & PDW (\%) \\
\hline Anemia & $98(66.2 \%)$ & $84781 \pm 30261.39$ & $8.44 \pm 1.71$ & $11.65 \pm 2.40$ \\
\hline Leukemia & $15(10.1 \%)$ & $77000 \pm 32526.91$ & $9.60 \pm 0.57$ & $15.35 \pm 5.16$ \\
\hline Pancytopenia & $28(18.9 \%)$ & $94733 \pm 29504.16$ & $8.50 \pm 1.62$ & $11.20 \pm 1.69$ \\
\hline Postchemotherapy & $6(4 \%)$ & $75895 \pm 22536.13$ & $8.60 \pm 0.57$ & $11.33 \pm 1.33$ \\
\hline Aplastic anemia & $1(0.6 \%)$ & 76667 & 9.13 & 8.1 \\
\hline
\end{tabular}

Table 5: Platelet parameters in abnormal pooling of platelets- Group $\mathbf{C}$

\begin{tabular}{|c|c|c|c|c|}
\hline Group C cases & Number (\%) & PC & MPV (fL) & PDW (\%) \\
\hline Splenomegaly & 4 & $110750 \pm 28087.66$ & $10.6 \pm 1.25$ & $15.25 \pm 1.82$ \\
\hline
\end{tabular}

Table 6: Statistical comparison of platelet parameters with control group.

\begin{tabular}{|l|c|c|c|}
\hline Platelet parameter & Group A Vs Control & Group B Vs Control & Group C Vs Control \\
\hline Platelet count & $\mathrm{t}=-40.4$ & $\mathrm{t}=-38.092$ & $\mathrm{t}=-10.179$ \\
& $\mathrm{p}<0.05$ & $\mathrm{p}<0.05$ & $\mathrm{p}=0.001$ \\
\hline MPV & $\mathrm{t}=10.694$ & $\mathrm{t}=-10.297$ & $\mathrm{t}=0.717$ \\
& $\mathrm{p}<0.05$ & $\mathrm{p}<0.05$ & $\mathrm{p}=0.524$ \\
\hline PDW & $\mathrm{t}=4.672$ & $\mathrm{t}=-5.672$ & $\mathrm{t}=1.86$ \\
& $\mathrm{p}<0.05$ & $\mathrm{p}<0.05$ & $\mathrm{p}=0.154$ \\
\hline
\end{tabular}

For Table 6, $\mathrm{p}<0.05$ is significant.

\section{Discussion}

Among the various constituents of the blood, platelets (thrombocytes) are crucial in stopping bleeding by aiding in clotting processes. These platelets take birth from megakaryocytes in the bone marrow. When the number of platelets falls below normal levels $<1,50,000 / \mathrm{ul}$, the condition is referred to as thrombocytopenia (TCP). ${ }^{1-4}$ The cause for this decrease in platelets can be broadly attributed either to their accelerated destruction, impaired production or abnormal pooling in spleen and it was this classification that formed the basis for our study. ${ }^{1-4}$ Accelerated destructive TCPs are due to extramedullary platelet destruction with normal or increased bone marrow productions. Impaired productive TCPs result from decreased bone marrow production either due to primary or secondary bone marrow diseases. Splenic pooling are the various causes leading on to splenic sequestration of platelets. Clinical methods alone are difficult to assess the mechanism for TCP. Analysing the platelet parameters play a paramount role in assessing the mechanism for TCP. ${ }^{1-7}$
In day to day life, a well prepared peripheral blood smears can be used to know the platelet number, size, distribution and morphology under microscopy. ${ }^{1-4}$ With recent advances in technology, automated cell counters give better information of these platelet parameters as platelet count, MPV and PDW. MPV means mean platelet volume which is a machine calculated measurement of the average size of platelets found in blood. Normal range is given as 7.5- $11.5 \mathrm{fl}$. MPV is thought to reflect the changes in rate of platelet production, accelerated production leads to larger platelet size and impaired production leads to smaller and aged platelets. Hence the MPV values can be used to make inference about platelet production in bone marrow or platelet destruction. High MPV values are found in cases with accelerated destruction and lower MPV values in impaired production TCPs..$^{1,2,4,5-9}$ PDW means platelet distribution width an indication of variability in the size of platelets and is increased in the presence of platelet anisocytosis. Normal range is given as 9-14 fl. The activation of the platelets causes some morphological alteration by becoming larger, spherical shape and formation of pseudopodia affecting PDW. 
Hence higher PDW values are seen in accelerated destruction TCP due to release of heterogenous population of platelets which vary in their size (anisocytosis). ${ }^{1,2,4,5-9}$

In the present study out of 700 cases; 617 cases of TCP patients and controls had all the details which were analyzed. 83 cases in the present study did not show values of platelet parameters. In severe cases of TCP; platelet histograms shows deviations from normal bell shaped curve and platelet indices cannot be measured. In our study also severe TCP cases did not show platelet parameters in automated machines; similar problem was also encountered in other studies. ${ }^{10-12}$ The majority of the patients in the present study were males $399(64.7 \%)$ and the remaining 218 $(35.3 \%)$ were females. Ages of the patients ranged from 1 day (neonatal cases) to 85 years similar to other studies. ${ }^{8,13-20}$

Patients were categorized into three groups according to the predominant mechanism of TCPs. Majority of the cases in the present study were of group A $(75.4 \%)$, followed by group B (24\%) and group C $(0.6 \%)$ similar to the study done by Reddy RS et al, Praveen $\mathrm{S}$ et al, Katti $\mathrm{T}$ et al and Numbenjapon $\mathrm{T}$ et al in contrast to study by Khaleel $\mathrm{KJ}$ et al and Liqaa $\mathrm{M}$ et al showed group B being the majority. (Table 5)

Platelet parameters were studied in various groups of TCPs. In the present study group A included infections, neonatal TCPs, cardiac cases, pregnancy induced TCPs, renal, liver, sepsis, burns and immune thrombocytopenias (ITP) accounting to $75.3 \%$ of which infections were the majority number of cases similar to other studies. ${ }^{8,13}$ In contrast, studies done by Numbenjapon $\mathrm{T}$ et $\mathrm{al}^{15}$ and Khaleel KJ et $\mathrm{al}^{16}$ found ITP being the majority of cases in group A. In the present study highest MPV and PDW values in group A category were seen in ITP cases similar to the other studies. ${ }^{8,9,13-22}$ This increase in MPV and PDW is considered to be due to immune destruction of platelets leading on to accelerated production of larger sized platelets. ${ }^{8,9,13-22}$

Group B category included disorders associated with TCPs due to inadequate platelet production from bone marrow. Our study showed $23.9 \%$ of cases in this group which included anemias, leukemias, post chemotherapy cases and aplastic anemia of which anemias were the predominant cases similar to other studies. ${ }^{8,13}$ Conflicting results were seen in a study by Numbenjapon $\mathrm{T}$ et $\mathrm{al}{ }^{15}$ who found leukemias and MDS and a study by Khaleel $\mathrm{KJ}$ et $\mathrm{al}^{16}$ found postchemotherapy cases being the majority cases in group B. Compared to group A; group B showed lesser MPV and PDW values similar to the other studies. These decreased values are considered to be due to impaired production of platelets with compensatory production of smaller aged platelets. , $^{8,9,13-22}$

Normal spleen sequesters approximately one third of the total platelets hence platelet count declines inversely and proportionately to increasing spleen size. ${ }^{1-4}$ This is the group $\mathrm{C}$ category comprising of congestive splenomegaly cases suggesting abnormal platelet pooling. ${ }^{1-4}$ In the present study this category attributes to the least number of cases $0.6 \%$ similar to other studies. This group also had higher MPV, PDW similar to group A possibly due to splenic pooling leading on to increased production of larger platelets. ${ }^{8,9,13-22}$

MPV and PDW values in group $\mathrm{A}$ were $10.15 \pm 1.30 \mathrm{fL}$ and $14.44 \pm 2.35 \%$, in group B $8.52 \pm 1.69$ $\mathrm{fL}$ and $12.00 \pm 2.64 \%$ and group C were $10.6 \pm 1.25 \mathrm{fL}$ and $15.25 \pm 1.82 \%$ respectively. Similar ranges of values were also obtained in other studies. ${ }^{8,13,16}$ (Table 6)

Platelet parameters among various groups were statistically analysed and results showed that MPV and PDW were significantly higher in accelerated destruction group compared to impaired production group similar to the other studies. ${ }^{8,9,13-22}$ These results exemplify the fact that in accelerated destruction group, bone marrow tries to compensate for the destructed platelets by actively producing younger larger platelets of varying sizes. But in contrast studies done by Elsewefy et $\mathrm{al}^{22}$ and Borkataky et $\mathrm{al}^{9}$ showed conflicting results as no significant difference in the MPV between either of the groups. The studies done by Tomito et al, ${ }^{23}$ Nakadate et $\mathrm{al}^{24}$ and Baynes et $\mathrm{al}^{25}$ found low MPV in accelerated destruction group especially in acute ITP cases and concluded saying that younger platelets may not always be larger but could be smaller in size with low MPV. Also a study done by Xu et $\mathrm{al}^{26}$ found higher PDW in impaired production group and stated that this is due to dysplasia of hematopoiesis.

\section{Conclusion}

Platelet parameters like MPV and PDW obtained by automated cell counters together with platelet counts help us to know the pathomechanism of various causes of TCPs either due to accelerated destruction, impaired production or splenic pooling. This further helps us in better diagnosis, evades invasive procedures and easies further management. Hence the present study highlights the paramountcy of platelet parameters in TCP cases and adds as an adjunct to the routine investigations.

\section{References}

1. Lee GR, Foerster J, Lukens J et al: Wintrobes clinical hematology, 12th edition, Lippincott Williams and Wilkins. 2009; 277-91.

2. P Greer, Daniel A Arber, Bertil Glader, Alan F List, Robert T Means, Frixos Paraskevas, George M. Rodgers in Williams's hematology Chapter 49 Thrombocytopenia 8th edition MacGraw-Hill. 2010;1101-02.

3. Harrison C and Radia D. Haematology: Part 1. Medicine. 2013;41:193-256.

4. Singh T, Singh N. Formation of blood cells: Bone marrow biopsy. In: Saxena R, Pati HP, Mahapatra M, editors. De Gruchy's Clinical Haematology in Medical Practice. $6^{\text {th }}$ Adapted Edition, Ch. 1. New Delhi: Wiley. $2013 ; 8$. 
5. Jackson SR, Carter JM. Platelet volume: laboratory measurement and clinical application. Blood Rev. 1993;7:104-13.

6. Farias MG, Schunck EG, Dal Bó S, de Castro SM. Definition of reference ranges for the platelet distribution width (PDW): a local need. Clin Chem Lab Med. 2010;48:255-57.

7. Vinholt PJ, Hvas AM, Nybo M. An overview of platelet indices and methods for evaluating platelet function in thrombocytopenic patients. Eur $J$ Haematol. 2014;92(5):367-76.

8. Reddy RS, Phansalkar MD, Ramalakshmi PVB. Mean Platelet Volume (MPV) in Thrombocytopenia. J Cont Med A Dent. 2014;2(2):45-50.

9. Borkataky S, Jain R, Gupta R, Singh S, Krishan G, Gupta $\mathrm{K}$, et al. Role of platelet volume indices in the differential diagnosis of thrombocytopenia: a simple and inexpensive method. Hematology. 2009;14:182-6.

10. Tocantis LM. The blood platelets-past, present and future. In: Johnson SA, Monto RW, Reback JW, Horn RC: Blood platelets: Henry Ford hospital international symposium, 1st edition; Little, Brown and company, Boston.1961;122-25

11. Niethmmer AG, Forman EN. Use of the platelet histogram maximum in evaluating thrombocytopenia. Am J Hematol. 1999;60(1):19-23.

12. Kaito K, Otsubo H, Usui N, Yoshida M, Tanno J, Kurihara E, Matsumoto K, Hirata R, Domitsu K, Kobayashi M. British J of Haemetol. 2005;128(5):698702.

13. Parveen S, Vimal M. Role of Platelet Indices in Differentiating Hypoproductive and Hyperdestructive Thrombocytopenia. Annals of Pathol Lab Med. 2017;4(3):288-91.

14. Katti T, Mhetre S, Annigeri C. How far are the platelet indices mirror image of mechanism of thrombocytopeniamystery still remains? Int J Adv Med. 2014;1(3):200-5.

15. Numbenjapon T, Mahapo N, Pornvipavee R, Sriswasdi C, Mongkonsritragoon $\mathrm{W}$, Leelasiri A, et al. A prospective evaluation of normal mean platelet volume in discriminating hyperdestructive thrombocytopenia from hypoproductive thrombocytopenia. Int J Lab Hematol. 2008;30(5):408-14.

16. Khaleel KJ, Ahmed AA, Anwar MAA. Platelet indices and their relations to platelet count in hypoproductive and hyper-destructive Thrombocytopenia. Karbala J Med. 2014;7(2):1952-58.
17. Liqaa M, Al-Sharifi M. Value of Platelet Indices in Diagnosing Etiology of Thrombocytopenia. Journal of Babylon University/Pure and Applied Sciences. 2018;26(3):201-5.

18. Shah AR, Chaudhari SN, Shah MH. Role of Platelet Parameters in Diagnosing Various Clinical Conditions. Natl J Med Res. 2013;3(2):162-5.

19. Gulati I, Kumar H, Sheth J, Dey I. Diagnostic implication of mean platelet volume in thrombocytopenia. Med J DY Patil Univ. 2017;10:370-5.

20. Khairkar SP, More S, Pandey A, Pandey M. Role of mean platelet volume (MPV) in diagnosing categories of thrombocytopenia. Indian J of Pathol and Oncol. 2016;3(4):606-610.

21. Reddy RS, Khan MI, Phansalkar MD. Platelet Distribution Width (PDW) in Thrombocytopenia. Indian Medical Gazette. .2015;169-71.

22. Elsewefy DA, Farweez BA, Ibrahim RR. Platelet indices: consideration in thrombocytopenia. Egypt J Haematol. 2014; 39: 134-8.

23. Tomita E, Akatsuka JI, Kokubun Y. Differential diagnosis of various thrombocytopenias in childhood by analysis of platelet volume. Pediatr Res. 1980;14(2):1337.

24. Nakadate H, Kaida M, Furukawa S, Ishii M, Higashihara M. Use of the Platelet Indices for Differential Diagnosis of Pediatric Immune Thrombocytopenic Purpura (ITP). Blood. 2008;12(11):4557-60.

25. Baynes RD, Lamparelli RD, Bezwoda WR, Gear AJ, Chetty N, Atkinson P. Platelet parameters. Part II. Platelet volume-number relationships in various normal and disease states. South Afr Med J. 1988;73(1):39-43.

26. Xu R-L, Zheng Z-J, Ma Y-J, Hu Y-P, Zhuang S-H. Platelet volume indices have low diagnostic efficiency for predicting bone marrow failure in thrombocytopenic patients. Exp Ther Med. 2013;5(1):209-14.

How to cite this article: Mala K.G, Bhandari
B.J, Kittur S.K. Paramountcy of platelet
parameters in thrombocytopenia- Our hospital
experience. Indian J Pathol Oncol.
2018;5(4):558-562.

